\title{
A new framework for passenger experience
}

\begin{abstract}
Passenger experience is getting more and more attention among airline companies. ${ }^{1}$ Airline companies are facing new demands for designing better passenger experiences to insure their future survivability in this competitive industry. However, very little is known on what passengers really need during flight. ${ }^{2}$ Passenger comfort has been the subject of numerous studies for decades. That is because it influences on passengers' wellbeing, satisfaction, system acceptance and consequently choices of future. ${ }^{3}$ Even though comfort plays a great role on passenger experience, comfort definitions are usually rather vague and general. Also, despite the fuzziness of the concept, a number of common issues are agreed upon in the literature which are best described by De Looze et al., ${ }^{4}$ as follows:

a. Comfort is a construct with subjective and personal elements,

b. Various factors influence comfort (psychological, physiological and physical),

c. Comfort is a reaction to the environment.

In this paper, we introduce a new approach for defining passenger experience. We base passenger experience on the 'activities' that passenger do during flight. Each activity, whether it is a rule-based activity (listening to crew announcements) or optional-based activity (watching IFE etc) act as experience components that all together create the overall passenger experience. Several studies confirm that before redesigning the interior or inflight services, it is useful to elicit passengers' knowledge on their experience related to various in-flight activities. ${ }^{5,6}$ Also, Smulders et al., ${ }^{6}$ and Lille et al., ${ }^{1}$ showed that passenger satisfaction could be a result of what passengers tend to do. We also offer a new model on how these activities in addition to various factors lead to specific passenger experiences.
\end{abstract}

Keywords: passenger experience, Comfort, activities, cabin design, cognitive functions, human-centered design

\author{
Volume 3 Issue 2 - 2019
}

\author{
Golnoosh Torkashvand \\ Human Centered Design, Florida Institute of Technology, USA
}

Correspondence: Golnoosh Torkashvand, Human Centered Design, Florida Institute of Technology, USA, Email Gtorkashvand2014@my.fit.edu

Received: April 18, 2019 | Published: May 28, 2019

\section{Introduction}

In the ever-growing human-centered design approach, it is necessary to consider all human assets from very early stages of design cycle. By moving from purposes to means we can insure human-centered, sustainable systems that incrementally become mature by several iterations. ${ }^{7}$

\section{Comfort as experience}

The context of comfort does differ. However, there is a general notion in the word comfort. Comfort is described as 'freedom from pain, well-being' in Dutch dictionaries like the Van Dale 2000. In these dictionaries comfort is also translated as convenience of the interior. Many people associate comfort with the interior. In scientific literature comfort can be a pleasant state of physiological, psychological and physical harmony between a human being and the environment or a sense of subjective well- being. According to De Looze et al., ${ }^{4}$ comfort is a subjective experience. A product can never be comfortable. It becomes comfortable (or not) when it is used. The user decides whether a product is comfortable or whether it leads to discomfort. This complicates the construct of comfort, because it is not known how every individual will react to a product. For Instance, on a long-distance airplane flight passenger one may feel that back comfort or discomfort is of greatest importance, while passenger two wants a reduction in noise and passenger three needs more space. It is complicated and potentially cost prohibitive to provide all passengers with an ideal design to address comfort situations specific to each passenger.
Passenger comfort is influenced by many inputs from the cabin interior environment. Despite the very diverse definitions in the literature, the recent research confirms that passenger comfort could be classified into two categories. ${ }^{3}$ The first category, which covers a major body of research on aircraft design, focuses on issues in relation to physical environmental which have an impact on passengers' perception of comfort, for instance thermal, acoustic, air quality and such. The research on this category aims at providing objective measures with the aim of preventing physical pain or health issues and meeting higher standards with respect to engineering aspects of the aircraft cabin design. The second category takes on a holistic approach toward the general comfort perception of passengers and typically provides information about the different features or qualities within the aircraft cabin which influence passenger comfort. ${ }^{3}$ While the former approach provides technical measurements for engineers. ${ }^{8}$ The latter approach could potentially guide the design of cabin $^{9,10}$ and services $^{11}$ (Figure 1).

History: It means that for ensuring comfort we should cover at least the level of comfort people are used to. We also, evaluate the appearance and styling of a product with our past as a reference and we always evaluate the service related to past experiences.

State of Mind: Emotions, feelings, and mood play a role in the way someone evaluates a product businessman who have to be on time and passengers who go to hotel have different state of minds.

Visual input: Humans see a shape, size, glossiness, and Lightness of an object and form an impression on comfortable it is. This visual impression is not an objective quality, but is a mental construct Color also plays an important role. 


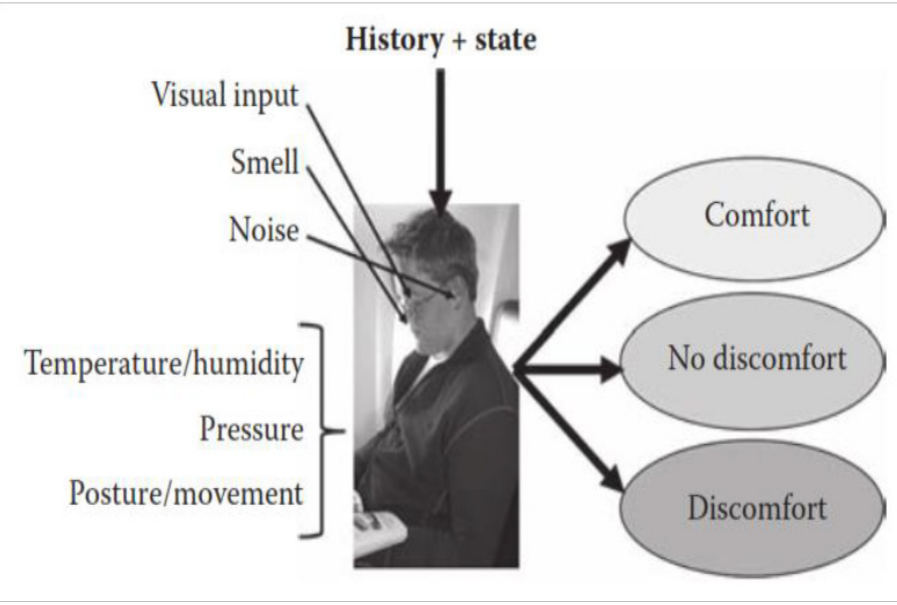

Figure I The comfort input/output schema adapted from Vink \& Brauer. ${ }^{9}$

Smell: Smell also influences our perception of comfort. Different authors report that smell influences our experiences and that we are mostly not aware of this effect.

Noise: Is a type of input that can influence comfort positively or discomfort negatively. Noise of an engine while working in an earthmoving machine can lead to discomfort, while the sound of a Harley Davidson (a motorcycle brand) is a kind of music to some of us.

Temperature and humidity: Many studies indicate that having control on your own climate influences your comfort.

Pressure and touch: Mergl made a pressure map of the human body for the ideal seat pressure distribution (see Chapter 2). This ideal pressure distribution leads to a high comfort rating. Apart from pressure, we have also tactile influences of materials. Textures of handles have an influence on the feeling of comfort. Sonneveld, in her $\mathrm{PhD}$ thesis, describes how we can take these feelings into account during the design process.

Posture and movements: To avoid imposing a restricted posture, it is Important for airplanes to make variation in possible posture.

Figure 2 illustrates the most important factors influencing comfort. ${ }^{12}$ A bad smell has so much influence that it overrules all other aspects. In fact, smell, light, vibrations, noise, and climate are at a rather high standard in current airplanes. This results in the anthropometry being the focus of more attention. Attention to anthropometry is of little importance if the other aspects are not acceptable. In commercial aviation, service may merit a level above anthropometry in the Bubb discomfort pyramid.

From lack of discomfort to pleasure experience

As the meaning comfort suggests, it is either lack of pain and discomfort or the neutral feeling of no comfort or discomfort. In order to focus on good passenger experience which brings about competitive advantages to the airlines, we need to focus on comfort experience which is beyond those two definitions.

\section{Activity as experience portions}

As this paper suggests, passenger activities are a great basis for granulating the vague nature of passenger experience into measurable components. In a previous study by Torkashvand et al., ${ }^{13}$ a total of 23 activities were elicited by use of retrospective brainstorming method. These activities include:

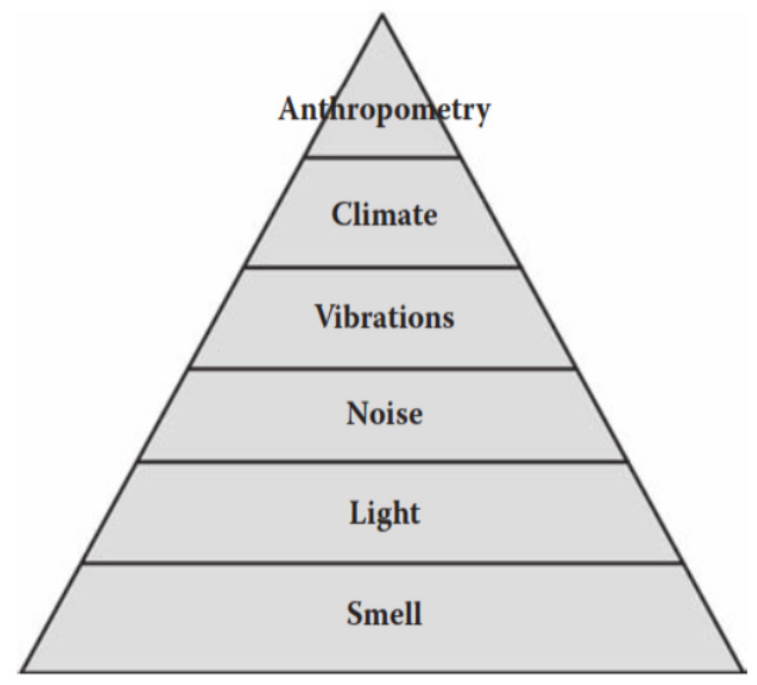

Figure $\mathbf{2}$ The discomfort pyramid based on the work of Bubb. ${ }^{12}$

a. Resting/Relaxing

b. Sleeping

c. Listening to Music

d. Reading books/magazines/e-reader

e. Talking to other groupmates

f. Talking to neighbors

g. Eating/drinking

h. Thinking and observing

i. Working on laptop, tablet etc.

j. Playing, working with cell phone

k. Watching in-flight movies

1. Checking real-time flight info.

$\mathrm{m}$. Walking in the cabin (exercise)

n. Taking care of family/kids

o. Being physically active/stretching

p. Looking outside of the window

q. Egress in/out of the seat

r. Using the restroom

s. Listening to flight communication

t. Boarding

u. Deboarding

v. Interacting with flight attendant

w. Adjusting seat features 
Knowing these activities is crucial to create a framework for measuring passenger experience. In addition, we still need to consider other factors that affect the ratings of each passenger on importance of and satisfaction raised by each of these activities. ${ }^{13}$

\section{Passenger experience model}

As the recent research study suggests, passenger satisfaction raised by performing the in-flight activities might contribute to a broader positive experience (Figure 3). The model suggests that in order to create a good passenger experience, we need to think about how each individual activity can be performed in the shadow of these factors:

a) Passenger profile

b) Resources

c) Context

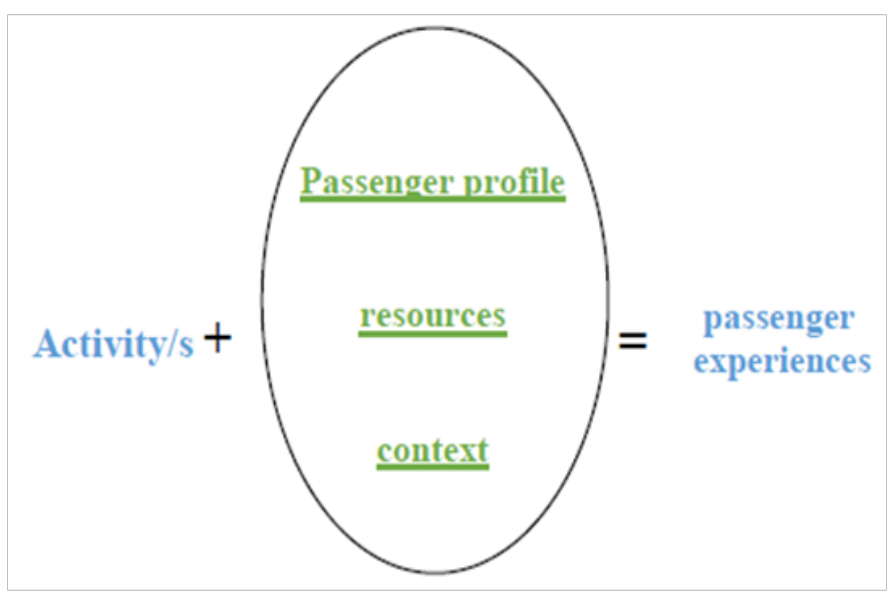

Figure 3 The passenger experience model.

Passenger profiles could vary on the attributes such as demographics, as well as cultural, psychological, ideological and social factors.

Resources include any technology, artifact, human, system, software or service component that is being implemented to help the passenger with getting the task done.

Context is a broad terminology with multiple meaning. It is about time, location and situation in which the activity is being performed. It also helps designers to envision future use possibilities by describing how people will use a system to accomplish work tasks and other activities. $^{14}$

\section{Scenarios examples for envisioning potential context}

\section{Activity: Boarding the aircraft, finding the seat}

Scenario 1: A female passenger with two children one is 1 year old and the other is 4 years old. She also has a luggage and her small handbag with her. In one other hand she is holding the boarding pass to check the seat number on. The younger child is crying and as she needs to pass the passenger who is placing a luggage in luggage bin, she needs to know where her seat is. She is trying to look at row numbers first and then the seat character. She feels nervous while the passenger behind is approaching her quickly. She needs to find her seat and feel more comfortable by settling down.

\section{Activity: taking care of children}

Scenario 2: The young parent has planned a journey to Asia. They have 3 kids aging 1, 4 and 7 . They have promised to make a very comfortable enjoyable experience for their vacation. 1 hour after takeoff the youngest child requires diaper change. The mom seems unhappy since there is no space to change the diaper comfortably

\section{Activity: interacting with flight attendants}

Scenario 3: A gentleman is travelling to visit an old friend in a country where the language is different from his language. He also is not able to speak in English. He has some headache and needs some pills to sooth his headache. He is not able to communicate with the flight attendant.

\section{Activity: Listening to flight communication}

Scenario 4: While the crew are showing the safety instructions, a group of friends are not listening. They just make fun of the gestures. After a while because of a sudden failure of the engine, the plane lands and the passengers are announced to leave the cabin very quickly. They are nervous and some are wandering where the exit doors are. ${ }^{15}$

\section{Conclusion}

This paper suggests that in order to enhance passenger experience, designers could focus on activities that passengers perform during flying. It is more attainable to focus on increasing the satisfaction by any individual activities that passengers perform during flying by taking into account the factors that influence it. A model is also proposed; it suggests that for raising a satisfaction in an activity, designers need to have in mind user profiles, the resources and the contexts (of use). In addition, we believe in human-centered design as an iterative practice. It is important to test users, problems and solutions over and over to validate our design are going to be responsive to a wide range of users. This paper brings about a practical approach to design for passenger cabins so that they can ensure comfort experience as well.

\section{Acknowledgments}

None.

\section{Conflicts of interest}

Authors declare that there is no conflict of interest.

\section{References}

1. De Lille C, Santema S, Bouwens J, et al. Designing the cabin interior knowing high and low peaks in a passenger flight. AEGATS Conference: Paris; 2016

2. Harrison A, Popovic V, Kraal BJ, et al. Challenges in passenger terminal design: A conceptual model of passenger experience. In Proceedings of the design research society (DRS) 2012 conference. Department of Industrial Design, Faculty of Architecture, Chulalongkorn University; 2012. 344-356 p.

3. Ahmadpour N. Comfort experience in everyday life events. In: Advances in Affective and Pleasurable Design. Springer; 2017. 625-632 p.

4. De Looze MP, Kuijt-Evers LF, Van Dieen J. Sitting comfort and discomfort and the relationships with objective measures. Ergonomics. 2003;46(10):985-997.

5. Hiemstra-van Mastrigt S. Comfortable passenger seats: Recommendations for design and research. Doctoral thesis Retrieved from Delft university; 2015. 
6. Smulders M, Berghman K, Koenraads M, et al. Comfort and pressure distribution in a human contour shaped aircraft seat (developed with $3 \mathrm{D}$ scans of the human body). Work. 2016;54(4):925-940.

7. Boy G. Orchestrating human-centered design. Springer Science \& Business Media; 2012.

8. Kok JC, Muijden JV, Burgers SS, et al. Enhancement of aircraft cabin comfort studies by coupling of models for human thermoregulation, internal radiation, and turbulent flows. Proceedings of the European Conference on Computational Fluid Dynamics; 2006.

9. Vink P, Brauer K. Aircraft interior comfort and design. FL: CRC press, 2011 .

10. Vink P, Bazley C, Kamp I, et al. Possibilities to improve the aircraft interior comfort experience. Applied Ergonomics. 2012;43(2):354-359.
11. Chen CF. Investigating structural relationships between service quality, perceived value, satisfaction, and behavioral intentions for air passengers: Evidence from Taiwan. Transportation Research Part A: Policy and Practice. 2008;42(4):709-717.

12. Bubb R. Sitting comfort. In: IQPC aircraft interior innovation. Hamburg; 2008 .

13. Torkashvand G, Stephane L, Vink P. Aircraft Interior Design and Satisfaction for Different Activities; A New Approach Toward Understanding Passenger Experience. International Journal of Aviation, Aeronautics, and Aerospace. 2019;6(2):1-17.

14. Carroll JM. Scenario-based design. In Handbook of human-computer interaction. North-Holland; 1997. 383-406 p.

15. Boy GA. Cognitive function analysis. Vol 2. Greenwood Publishing Group; 1998 